BIBLIOTIKA : Jurnal Kajian Perpustakaan dan Informasi

\title{
PERAN LITERASI BUDAYA DALAM SASTRA LISAN
}

\author{
Siti masitoh \\ Universitas Islam Negeri Maulana Malik Ibrahim Malang
}

\begin{tabular}{ll} 
A R T I C L E I N F O & A B S T R A C T \\
\cline { 2 - 3 } $\begin{array}{l}\text { Kata Kunci: } \\
\text { Cultural Literacy } \\
\text { Oral Tradition }\end{array}$ & $\begin{array}{l}\text { Texts cannot be separated from its context in order to reach the deeper understanding of } \\
\text { the text's significances. The same is thrue with the text of Murwakala. The readers will be } \\
\text { able to get better understanding of Murwakala's significances when the readers have got } \\
\text { sufficient knowledge of wayang (shadow theater) and ruwatan. It happens because the } \\
\text { Javanese have certain way how to have a look wayang. This article is aimed at presenting } \\
\text { the importance of having cultural literacy in understanding the significance of the oral } \\
\text { tradition. }\end{array}$
\end{tabular}

(c) 2017 BIBLIOTIKA Journal. All rights reserved

\section{PENDAHULUAN}

Murwakala adalah lakon yang biasa dipergunakan pada pertunjukan wayang kulit purwa dalam tradisi ruwatan. Ruwatan adalah upacara atau ritual yang dimaksudkan untuk membebaskan orang yang termasuk dalam kelompok sukerta yaitu orang-orang yang kejatuhan malapetaka yang kemudian akan menjadi makanan Bathara Kala (Rassers, 1982: 46). Ada sebagian orang yang masih percaya bahwa ruwatan merupakan tatacara hidup yang harus dipenuhi dan bila belum dipenuhi, maka orang tersebut merasa belum bebas dari kewajiban yang harus dilakukannya, andaikan tidak dapat memenuhi maka gelisahlah hidupnya (Subalidinata dkk, 1985: 3). Dengan kata lain, teks lakon Murwakala disampaikan oleh dhalang secara lisan dalam kemasan tradisi ruwatan yang dilakukan oleh sebagaian masyarakat Jawa. Dengan demikian ada dua elemen penting yang saling berkaitan, yaitu teks lakon Murwakala sebagai sebuah produk sastra lisan dan tradisi ruwatan sebagai sebuah produk budaya Jawa. Pemahaman tentang bagaimana masyarakat Jawa melihat dan memperlakukan tradisi ruwatan sangat diperlukan untuk mencapai pemahaman teks lakon Murwakala secara holistik. Hal ini terjadi karena pada hakekatnya teks ditentukan oleh konteksnya. Masyarakat Jawa mempunyai pandangan tertentu terhadap wayang dan ruwatan. Makalah ini membahas tentang pentingnya literasi budaya khususnya budaya Jawa yang berkaitan dengan tradisi ruwatan untuk lebih memahami makna teks lakon Murwakala.

\section{PEMBAHASAN}

Seperti yang sudah dikemukakan di atas bahwa teks lakon Murwakala diceritakan secara lisan oleh dhalang ruwat pada saat upacara ruwatan sehingga pembahasan tentang eksistensi teks Murwakala sebagai sebuah produk sastra lisan dan pembahasan tentang bagaimana masyarakat Jawa melihat pertunjukkan wayang sangat diperlukan. Pembahasan tersebut dapat diterangkan seperti berikut ini:

A. Kelisanan teks Murwakala.

Teks Murwakala yang dipagelarkan dalam upacara ruwatan dapat diklasifikasikan dalam tradisi lisan sebagian lisan berbentuk campuran unsur lisan dan unsur bukan lisan. Unsur lisan berupa lakon wayang kulit purwa yang berjudul Murwakala dan tembang yang mengiringi dhalang ruwat dalam menceritakan teks tersebut. Unsur bukan lisan berupa rangkain aktifitas yang harus dilakukan oleh dhalang, orang-orang yang diruwat, sesajen yang digunakan, perangkat alat karawitan dan niyaganya.

Sebagai produk tradisi lisan, Teks Murwakala mempunyai empat fungsi (Danandjaja, 2002), yaitu: (1) sebagai sistem proyeksi (cerminan) angan-angan suatu kolektif yaitu berkenaan dengan konsep sangkan paraning dumadi, konsep ini merupakan upaya masyarakat Jawa untuk melihat dirinya sendiri dengan menanyakan dari mana asalusulnya dan apa tujuan hidupnya, (2) sebagai alat legitimasi pranata-pranata kebudayaan, dalam masyarakat Jawa ada suatu kepercayaan bahwa anak-anak sukerta harus diruwat agar tidak jadi makanan Bathara Kala, (3) sebagai alat

\footnotetext{
*Corresponding author.

E-mail addresses: smasitoh68@yahoo.com(Siti masitoh)
} 
pendidikan, peristiwa-peristiwa yang dialami oleh setiap tokoh dalam teks Murwakala memberikan tuntunan kepada penonton, misalnya tentang pekerjaan yang baik, hubungan antara suami-istri, hubungan antara orang-tua dan anak, bagaimana selayaknya mengerjakan suatu pekerjaan, dan bagaimana kita memperlakukan alam, dan (4) sebagai alat pemaksa atau pengontrol agar norma-norma masyarakat selalu dipatuhi anggota kolektifnya, misalnya norma tentang empan-papan, lahirnya Bathara Kala karena kesalahan yang dilakukan oleh Bathara Guru yang tidak mengindahkan tentang norma empan-papan .

Kemudian, sastra lisan mempunyai ciri khusus dalam penggunaan bahasa yang disebut formulaik. Secara singkat dapat dikatakan bahwa formulaik adalah kelompok kata yang secara teratur dimanfaatkan dalam kondisi matra yang sama untuk mengungkapkan satu ide hakiki (Lord, 1976: 4). Pada dasarnya sastra lisan mempunyai fungsi yang sama sebagai wadah hikmah tradisional menunjukkan ragam yang berbeda - beda. Namun hampir selalu penggunaan formula dan unsur formulaik dalam ciptaan atau sastra lisan itu sangat menonjol. Pada sastra lisan pencerita mempunyai peran yang penting sebab dalam cerita yang dia pentaskan tersimpan informasi dan sistim nilai yang langsung relevan untuk masyarakat yang bersangkutan. Biasanya seorang pencerita melakukan penghafalan formula, unsur formulaik, peribahasa, pepatah dan petitih sebelum pentas tetapi setiap kali akan berpentas, dia menciptakan kembali secara baru dan spontan gubahannya. Formula yang terdapat pada lakon wayang berbentuk balungan lakon . Ki Suprapto,HS mendapatkan balungan lakon Murwakala dari gurunya yaitu Ki Panut dalam bentuk tulisan tangan . Balungan lakon Murwakala yang dimiliki oleh Ki Suprapto, HS adalah seperti berikut:

\section{MURWAKALA}

I. Suralaya : Guru, Nrodo, Bromo

Ngrembag : Goro-goro

Komo Salah dhateng:

1. Dikethok siyunge - kethokan siyung dipujo dadi pusoko: Kolonadah - Pulanggeni

2. Didhaku - dijenengake

3. Diparingi busono

4. Dititipi/ditulisi : Bathuk telak - dhadha - gigir - diwekas

5. Diparingi pangan : lobang manglung banyu tanpa rambatan, glagah rerayungan - padas gura-walan, bocah sukerta

6. Kolo mundur

7. Nrodo - Bromo - Kadhawuhan dateng utoro segoro

8. Umo gugat - sinabdo dadi Durgo/Pramuni kadhawuhan ngodhol Kolo

9. Durgo mundur mujo Wadubarat.

II. Kolo pethuk Joko Jatusmati- dioyak

Mlebu bumbung wungwang

Mlebu pawon - ngrubuhke dandang

Mlebu omah dandang ngelas

Pethuk Trunobapa - Bapatruno prang

Pethuk wong meteng gandulan lawang, angop disusupi Jatusmati

Kolo prentah Wadubarat jaga laire bayi

RUWAT KOLO

I. Utoro segoro : Wisnu -Nrodo - Bromo

Wisnu dadi Dhalang Kondhobawono

Nrodo dadi pangendhang-Pajak Dhalang Klungkungan

Bromo dadi panggender Saruni

Sami mandhap dhateng dhukuh Sumedhang Kawit

II. Sumedhang Kawit

Dhalang CS

Sing nanggap teko

budhalan

III. Kolo - Wadubarat lapur - budhalan nonton wayang

IV. Papan wayangan : sonteng Paruwatan trus tigas remo

Ki Suprapto, HS tidak hanya menggunakan balungan lakon di atas tetapi juga membaca teks Murwakala versi Kyai Panjang Mas, kemudian dalam penceritaannya kembali Ki Suprapto, HS melakukan beberapa perubahan baik berupa pengurangan ataupun penambahan adegan. Ki Suprapto, HS mengembangkan alur cerita dengan menambahkan beberapa peristiwa yang berhubungan dengan dumadine Kala, ruwat Kala dan ruwat Batari Durga. Peristiwa dumadine Kala menjelaskan tentang bagaimana terjadinya Batara Kala, proses pencarian identitas diri Batara Kala sampai pada permintaan fasilitas sebagai anak dewa yaitu permintaan nama, pakaian, dan makanan. Perjalanan Batara Kala tersebut diinterpretasikan sebagai proses sangkaning dumadi. Peristiwa dumadine Kala mendahului perjalanan Batara Kala mencari makanan manusia sukerta, kemudian ditambahkan lagi dengan peristiwa yang berhubungan dengan ruwat Kala dan ruwat Durga. Batara Kala dan Batari Durga minta diruwat oleh Dhalang Kandabuwana. Ki Suprapto, HS menceritakan bahwa Batara Kala minta diruwat supaya kehidupannya lebih baik, tentram , dan damai. Batara Kala diminta mengambil salah satu sesajen, mandi keramas, dan berlaku tirakat sebelum diruwat. Peristiwa tersebut menunjukkan bahwa Batara Kala diruwat dengan cara yang sama seperti ruwatan manusia sukerta pada umumnya. Batara Kala merasakan hidupnya lebih baik dan hatinya lebih tentram setelah diruwat dengan 
dibacakan mantram Gumbala Geni, kemudian Batara Kala meninggalkan tanah Jawa menuju Nuswakambana. Peristiwa ini menunjukkan terjadinya perubahan kondisi yang dialami oleh Batara Kala yaitu perubahan dari kondisi dimana Batara Kala mempunyai keinginan untuk memakan manusia, sehingga Batara Kala menjadi pengancam hidup manusia sukerta menjadi kondisi dimana Batara Kala merasa hidupnya lebih nyaman dan hatinya lebih tentram sehingga Batara Kala tidak perlu lagi memakan manusia sukerta. Peristiwa tersebut diinterpretasikan sebagai pencapaian tujuan hidup yaitu menuju kehidupan yang lebih baik. Dengan kata lain dapat dikatakan bahwa penambahan peristiwa ruwat Kala dan ruwat Durga memberikan makna paraning dumadi yaitu suatu pemahaman tentang apa tujuan hidupnya yaitu menuju ke kehidupan yang lebih baik atau menuju ke kesempurnaan hidup. Akhirnya, dapat dikatakan bahwa Ki Suprapto, HS mempunyai ciri atau kekhasan tersendiri dalam mementaskan lakon Murwakala pada upacara ruwatan Sukerta dan Sengkala. Kekhasan tersebut menunjukkan idiosinkretik Ki Suprapto, HS sebagai dhalang ruwat yang berasal dari Nganjuk Jawa Timur walaupun Ki Suprapto, HS membaca dan mempelajari balungan lakon Murwakala dari gurunya yaitu Ki Panut. Fakta tersebut menunjukkan bahwa setiap dhalang akan selalu berbeda dalam pertunjukannya. Temuan di atas memperkuat pendapat Jonathan Culler bahwa kompetensi pembaca dalam penelitian ini adalah dhalang akan menentukan performa. Kompetensi tersebut merupakan hasil komunikasi dialogis yang dilakukan oleh Ki Suprapto, HS terhadap alam (universe), artist (pembacaan naskah lain), dan audience dalam hal ini adalah kesepakatan yang dibuat antara Ki Suprapto, HS dengan panitia penyelenggara ruwatan masal.

Temuan ini juga memperkuat pendapat Becker bahwa sebuah teks selalu mengkomunikasikan masa lalu dengan masa kini, artinya apa yang dilakukan oleh Ki Suprapto, HS menunjukkan cara bagaimana Ki Suprapto, HS menceritakan lakon Murwakala dalam konteks kekinian. Tindakan yang dilakukan oleh Ki Suprapto, HS juga menunjukkan upaya untuk mengisi ruang kosong yang disediakan oleh penulis. Dengan kata lain, dapat dikatakan bahwa temuan ini memperkuat juga pendapat Iser tentang konsep ruang kosong, ruang yang disediakan oleh penulis, dimana pembaca secara kreatif, secara bebas dapat mengisinya.

Lebih lanjut, Lord (1976: 16- 20) menekankan tentang hal yang penting dalam sastra lisan yaitu upaya menunjukkan ketepatan bentuk lisan yang akan membedakannya dengan bentuk tulis dengan cara mengamati kebiasaan pencerita dalam menyampaikan cerita yang tidak tertulis dan melihat bagaimana bentuk cerita mereka dipelajari dan dipraktikan tanpa membaca dan menulis. Sastra lisan mengacu pada bentuk naratif yang disusun dengan melibatkan beberapa generasi pencerita yang tidak mengenal tulisan dan bentuk naratif ini tersusun dari rangkaian baris secara metrik yang membentuk formula dan mengandung tema. Formula biasanya mengungkapkan empat ide yaitu : (a) nama aktor atau tokoh, (b) kejadian utama the main action, (c) waktu, dan (d) tempat. Tokoh dalam Murwakala adalah Bathara Guru, Bathara Wisnu, Bathara Brahma, Bathara Narada, Bathara Kala, Bathari Durga, mbok Rondho, dan Jatusmati. Peristiwa penting dalam Murwakala adalah ketika terjadi perang argumentasi antara Dhalang Kandhabuwana dengan Bathara Kala. Dhalang Kandhabuwana dapat menjelaskan segala rahasia Bathara Kala, asal mulanya ( terjadinya) sampai pada perjalanan hidupnya. Sesudah mengakui keunggulan Dhalang Kandhabuwana maka Bathara Kala minta kepada Ki Dhalang agar membaca tulisan yang terdapat dibadannya. Setelah Dhalang Kandhabuwana dapat membaca semua huruf yang tertulis dibadannya, maka Kala minta supaya diruwat oleh Dhalang Kandhabuwana. Sebelum permintaannya dikabulkan, Dhalang meminta bukti bahwa Kala sungguh sungguh ikhlas untuk diruwat. Sebagai buktinya Kala memilih sajen kain mori putih, untuk membuktikan bahwa ia tulus dan ikhlas diruwat sehingga dapat kembali pada kesucian lagi.

Perangkat formula yang mengindikasikan waktu dalam Murwakala versi Ki Suprapto, HS tidak digambarkan secara jelas, namun versi Kyai Panjang Mas menjelaskannya yaitu saat terjadinya Kama Salah. Kama Salah terjadi ketika Bathara Guru sedang bercengkrama di tamansari waktu itu tepat waktu senja kala ( menjelang matahari terbenam) tiba - tiba tergugahlah hasrat rasa asmara Bathara Guru kepada Dewi Uma. Namun Dewi Uma menolak keinginan Bathara Guru itu maka jatuhlah sperma Bathara Guru ke dalam laut dan menjadi Kama Salah yang disebut Sang Kendhang Gumulung.

Perangkat formula yang mengindikasikan tempat dalam Murwakala terjadi di Khayangan dan bumi. Khayangan adalah tempat tinggal para dewa seperti Bathara Guru dan Bathari Uma yang tinggal di Khayangan Suralaya. Formula tempat yang menunjukan adegan yang terjadi di bumi terjadi pada adegan pangruwatan yang diadakan di Sumedang Khawit.

B. Wayang

Pagelaran wayang kulit purwa dalam pemahaman masyarakat Jawa khususnya dan Indonesia pada umumnya dipahami sebagai tontonan sekaligus tuntunan karena di dalamnya terkandung ajaran-ajaran moral yang luhur. Pengertian wayang dalam artian yang luas secara harafiah berarti sebuah bayangan, sedangkan kalau dilihat dari wujudnya adalah sebuah boneka bertangkai terbuat dari kulit yang dipahat pipih diberi warna atau dilukis sesuai dengan karakter dari tokoh-tokoh yang digambarkan (Purwadi, 2007: 1).

Pagelaran wayang senantiasa mengandung nilai hidup serta kehidupan luhur yang dalam setiap akhir cerita atau lakonnya memenangkan kebaikan dan mengalahkan kejahatan. Hal itu mengandung suatu ajaran bahwa perbuatan baiklah yang akan unggul, sedangkan perbuatan jahat akan selalu menerima kekalahannya (Haryanto, 1992: 2). Melihat kenyataan begitu besarnya peran wayang dalam kehidupan orang Jawa, maka tidak berlebihan bila dikatakan bahwa wayang merupakan salah satu identitas utama manusia Jawa. Masyarakat Jawa gemar beridentifikasi dengan tokoh-tokoh wayang tertentu dan bercermin serta mencotoh padanya dalam melakukan perbuatan sehari-hari (Marbangun Hardjowirogo, 1994: 33).

Seni pedalangan mengandung banyak bahasa simbol kehidupan yang lebih bersifat rohaniah daripada jasmaniah. Jika orang melihat pagelaran wayang, yang dilihat bukan wayangnya, melainkan masalah yang tersirat dalam lakon wayang itu. Perumpamaan ketika orang melihat di kaca rias, orang bukan melihat tebal dan jenis kaca rias itu, melainkan melihat apa yang tersirat dalam kaca tersebut. Orang melihat bayangan di kaca rias. Oleh karenanya, 
kalau orang menonton wayang, bukannya melihat wayang, melainkan melihat bayangan (lakon) dirinya sendiri (Sri Mulyono, 1978: 15-16).

\section{Ruwatan}

Ruwatan berasal dari kata ruwat artinya: bebas, lepas. Kata mangruwat atau ngruwat artinya membebaskan, melepaskan. Dalam tradisi lama atau kuno yang diruwat adalah makhluk yang hidup mulia atau bahagia ,tetapi kemudian berubah menjadi hina dan sengsara. Maka mereka yang hidup sengsara atau hina itu harus diruwat, artinya dibebaskan atau dilepaskan dari hidup sengsara. Dalam Kamus Besar Bahasa Indonesia, kata ruwat berarti : pulih kembali sebagai keadaan semula (tentang jadi-jadian, orang kena tulah, dan sebagainya) dan terlepas (bebas) dari nasib buruk yang akan menimpa (bagi orang yang menurut kepercayaan akan tertimpa nasib buruk seperti anak tunggal dan sebagainya)(Kamajaya dkk, 1992: 10).

Kemudian, orang yang terkena malapetaka tidak sama kenyakinan dan kondisinya. Bagi yang mendalam kenyakinannya, mereka menganggap ruwatan adalah hal penting yang harus dilaksanakan sebaik-baiknya. Mereka akan berusaha keras untuk dapat membebaskan diri dari malapetaka dan melaksanakan ruwatan sebaik-baiknya. Sedangkan bagi mereka yang kurang yakin, apalagi kurang mampu, mereka akan mengambil sikap lain, yaitu ruwatan ala kadarnya. Bahkan bagi yang tidak percaya, tetapi tidak bisa menghindar dari adat ruwatan itu, mereka bersikap lunak misalnya dengan cara bela yaitu ikut orang lain (Teddy Rusdy, 2012: 2). Dengan kata lain, dapat dikatakan bahwa upacara ruwatan berkaitan dengan kepercayaan penghilangan pengaruh tidak baik pada diri seseorang, menghapuskan diri dari kutukan tidak baik, serta pembebasan dari kemalangan atau kesialan seseorang dalam mengaruhi kehidupan sehari-hari (Teddy Rusdy, 2012: 3).

Ruwatan yang sering dilakukan oleh orang Jawa adalah ruwatan dengan menggelar pertunjukan wayang kulit dengan mengambil lakon Murwakala. Upacara ruwatan biasanya dilengkapi dengan sejumlah sesajen tertentu dan dilakukan dengan tata-cara tertentu pula.Ruwatan dilakukan dengan mempergelarkan wayang karena lakon-lakon wayang menunjukkan filsafat dan ajaran hidup guna menghadapi tantangan dan kesulitan hidup. Jadi, pergelaran wayang mengandung berbagai simbol kehidupan dan memiliki makna filsafat dan nilai-nilai sosial budaya yang tinggi seperti : (1) kelir wayang yang terbuat dari kain berwarna putih merupakan simbol dari alam semesta. Awal mulanya adalah awang-uwung (kosong tidak berpenghuni). Barulah setelah Tuhan menciptakan manusia, hewan , tumbuhan, makhluk gaib, alam semesta tersebut menjadi penuh dengan cerita kisah perilaku mereka. Dengan demikian, pergelaran wayang kulit dapat dipahami sebagai perlambang kehidupan manusia: lahir, hidup, dan mati lengkap seluruh pengungkapan potensi batin dan fisikal yang dimiliki, (2) blencong atau lampu yang dipasang di depan kelir melambangkan matahari. Tanpa adanya cahaya dari sana alam semesta akan gelap gulita, dan seluruh kejadian tidak akan tampak, (3) dhalang sebagai sutradara dalam pergelaran wayang sangat menentukan bagaimana suatu kisah dimainkan. Termasuk siapa yang menang, yang kalah, yang mati, yang bahagia, dan selajutnya. Dalam konteks spiritualisme, dhalang adalah simbol Tuhan yang dapat memainkan seluruh kehidupan umatNya, (4) gamelan pengiring pergelaran diibaratkan masyarakat luas yang memberikan dukungan terhadap peristiwa apapun yang terjadi pada kelir (jagad pewayangan) ( Santoso, 2011: 208-209).

Lakon yang dimainkan dalam upacara ruwatan adalah Murwakala. Istilah Murwakala adalah bahasa perlambang atau simbol untuk peristiwa yang meninpa atau dialami manusia. Murwa berarti awal mula atau purwa berarti permulaan dari kala berarti waktu. Murwakala berarti asal mula sang waktu atau sangat (saat yang persis tepat bertalian dengan baik-buruk atau untung-malang). Sangat ialah kurun waktu tertentu yang sangat singkat menurut perhitungan waktu tarikh suryakala (perhitungan tahun kalender menurut sistem edar matahari) yang semula diambil dari tarikh Jawa Asli Pranata Mangsa dan kemudian diadobsi oleh Aji Saka, Brahmana Hindu yang datang ke Jawa dari India. Perhitungan sangat (waktu tepat ketika itu) yang didasarkan kepada suryakala (peradaran kalacakra= matahari), dipercaya memiliki kalahala (sa' at gangguan) atau kala-bendu (benah, tulah, atau sebab akibat), sa' at jelek (banyak bencana), yakni pada empat sa' at (sangat) yaitu : (1) sa' at gagat-esuk, gagating raina (pada saat terbit fajar),(2) sa' at surya tumumpang aksa (tengah hari saat matahari tepat di atas kepala), (3) sa' at sandyakala/sandhekala (senjakala), (4) sa' at candra tumumpang aksa (tengah malam saat bulan purnama tepat di atas kepala). Pada keempat sa' at tersebut, orang diwajibkan berada dalam kondisi jagra (terjaga, bangun, sadar diri), berjaga-jaga terhadap kemungkinan adanya marabahaya. Semua orang harus sudah bangun tidur sebelum gagat-esuk (terbit fajar) yang biasanya ditandai oleh ayam jantan mulai berkokok. Pada sa' at surya tumumpang aksa (matahari tepat di atas kepala) semua orang harus menghentikan semua kegiatannya atau istirahat. Pada sa'at sandhekala/sandyakala (saat terbenamnya matahari) semua orang harus segera masuk ke dalam rumah atau berlindung dalam ruangan. Dan pada $\mathrm{sa}^{\prime}$ at tengah malam sewaktu bulan sedang purnama (bundar benar, pada tanggal 14-15 kalender Jawa) semua orang harus terjaga dan memanjatkan doa kepada Hyang Widi/ Yang Maha Kuasa. Menurut kepercayaan Jawa asli (Jawadwipa), dalam keempat sa' at itu diingatkan untuk jagra (terjaga, tak tidur, sadar diri) dan berjaga diri, lebih waspada karena di saat-saat itu ialah waktu yang dipercaya penuh dengan kalahala (saat gangguan) atau kalabendu (benah, tulah, saat jelek, banyak bencana) (Herusatoto, 2012: 36-40).

Dari keterangan di atas dapat dikatakan bahwa manusia yang punya tanda-tanda tertentu dalam posisi/kedudukan kelahirannya ataupun perbuatan/pekerjaannya yang sukerta/terusik atau salah kedaden akan terganggu dalam perjalanan hidupnya sepanjang waktu. Oleh karenanya perlu dibebaskan /diruwat dari gangguan atau bencana tersebut dengan memahami hakikat hidup manusia yang disimbolkan dalam pertunjukkan wayang dengan segala pirantinya dan dengan lakon Murwakala yang mengandung nasehat: (1) bangun dari tidurnya sa' at fajar menyingsing, segera mandi dan berbenah diri, sadar diri kepada Sang penciptanya (eling marang kang gawe urip) bahwa kehidupan dunia sudah dimulai, (2) berlindung di tempat teduh (istirahat) sa' at tengah hari, supaya tenaga tidak terkuras karena kelelahan, apabila tenaga terkuras, kondisi tubuh menurun dan dapat menyebabkan sakit. Di tengah hari, hendaknya kita juga berdoa kepada Sang Pencipta, (3) menghentikan segala pekerjaan harian ketika 56 | BIBLIOTIKA : Jurnal Kajian Perpustakaan dan Informasi 
matahari telah condong di Barat; berdoa mengucapkan terima kasih/ syukur atas keselamatan dalam melakukan pekerjaan pada hari tersebut, masuk ke dalam rumah dan mengucap syukur atas kenikmatan dan rizki yang diterimanya pada hari tersebut. Senjakala adalah waktu ketika cahaya sang surya menghilang dari bumi, suasana berpindah antara remang dan gelap. Keadaan demikian dapat membuat pandangan mata orang dan hewan menjadi tidak jelas, sehingga bisa saling bertabrakan atau tersandung-sandung, (4) memanjatkan doa, memohon ampunan, perlindungan, dan limpahan rizki. Sa' at bulan purnama penuh adalah ketika pengaruh gravitasi magnet dari planet bulan berada pada posisi paling dekat dengan bumi dan dapat menimbulkan suatu kekuatan magnetis yang besar dan mempengaruhi semua makluk hidup di bumi (Herusatoto, 2012: 40-41).

Ada persyaratan yang harus dilakukan oleh peserta ruwatan. Dalam teks Murwakala diwakili oleh tokoh Bathara Kala. Bathara Kala harus menjalankan beberapa prasyarat sebelum diruwat. Dengan menjalankan semua prasyarat tersebut, diharapkan ruwatan akan bisa berjalan dengan lancar. Prasyarat pertama adalah pemakaian kain mori. Semua peserta ruwatan harus memakai kain mori berwarna putih. Kain mori ini melambangkan kebersihan dan kesucian batin. Agar ruwatan bisa berjalan dengan baik, hendaknya peserta ruwatan harus membersihkan hati dan kemudian iklas dalam menjalankan ruwatan. Prasyarat kedua adalah jejamas atau mandi besar. Tujuan mandi besar adalah untuk membersihkan seluruh bagian tubuh. Jejamas juga melambangkan kebersihan hati. Kemudian setelah mandi besar, Bathara Kala diminta untuk tirakat. Tirakat bertujuan mengendalikan segala amarah yang dimiliki oleh manusia. Secara singkat dapat dikatakan bahwa dengan menjalankan semua prasyarat, semua peserta ruwatan akan siap menjalankan ruwatan dengan kebersihan fisik maupun mental, lahir maupun batin serta mengolah rasa dengan jalan tirakat.

Kemudian, lakon Murwakala dimainkan oleh Dhalang Kandhabuwana bukan tokoh lain karena Dhalang Kandhabuwanalah yang mampu meruwat semua tokoh sukerta dan penganyam-anyam. Dhalang Kandhabuwana adalah tokoh yang memahami dan mampu menceriterakan perihal kehidupan di dunia dan mampu menyebarkan kawruh sejatining urip atau pengetahuan tentang hakikat hidup agar luput dari sengsara. Tindakan ini ditunjukkan oleh Dhalang Kandhabuwana ketika membaca semua tulisan yang ada pada empat bagian pada tubuh Bathara Kala yaitu: caraka balik, sastra telak, sastra binedhati dan sastra gigir.

Keempat sastra tersebut ditulis pada dahi, telak atau mulut, dada, dan punggung. Caraka Balik adalah huruf yang terdapat di dahi yaitu huruf Jawa yang dibaca terbalik. Huruf ini adalah Caraka Balik Pertama yang terdiri dari : nga, tha,ba, ma, nya, ya, ja, dha, pa, la, wa, sa, ta, da, ka, ra, ca, na, dan ha. Aksara Telak adalah huruf yang terdapat pada langit-langit atau telak yaitu Caraka Balik Kedua yang teridi dari : ha, ma, pa, ma, ta, dha, ga, ca, sa, ja, ba, ra, wa, ya, tha, ka, la, nya, tha. Caraka Balik adalah huruf Jawa yang dibaca terbalik. Asal - usul terbentuknya huruf Jawa adalah : hana- ca- ra-ka menunjukkan( dua utusan) yaitu dua abdi setia Empu Sengkala bernama Dora (si pembohong) dan Sembada (si perwira). Pada saat Empu Sengkala diangkat menjadi Raja Medangkamulan, Dora diutus mengambil keris pusaka yang ditinggalkan di pertapaan, dijaga oleh Sembada, dengan pesan,"Jangan diserahkan kepada siapapun kecuali kepadaku". Da-ta-sa-wa-la (lalu bertengkar) karena Dora meminta kepada Sembada agar keris pusaka diserahkan kepadanya dan Sembada bersikeras mempertahankan keris itu sesuai dengan pesan Raja Medangkamulan. Pa-dha-ja-ya-nya (sama-sama kuat/saktinya), keduanya bersikukuh pada argument masing-masing, kemudian bertengkar dan berkelahi memperebutkan keris. Keduanya sama-sama saktinya sehingga pertempuranpun semakin seru dan berlangsung lama. Ma- ga- ba-tha-nga (menjadi mayat), keduanya sama-sama berkeras hati, tegar mempertahankan pendiriannya sampai akhirnya keduanya mati, berebut dan saling tusuk menusuk dengan keris pusaka itu sendiri. Sekian lama Empu Sengkala menanti Dora dan Sembada, namun tak kunjung datang. Maka dia pun menyusul ke pertapaan dan menemukan keduanya telah mati. Barulah ia sadar bahwa ia lupa bahwa kedua abdi setianya itu tidak pernah bisa akur karena keduanya mempunyai karakter yang berbeda. Dora mempunyai karakter yang culas, pembohong, dan penipu namun cekatan dan setia. Sementara Sembada mempunyai karakter ksatria, jujur, teliti, kukuh pendirianya, dan cerdik namun lamban tetapi taat. Secara singkat caraka balik dan sastra telak menunjukkan adanya dua hal yang berbeda yang ada di otak dan dimulut. Sastra Binedhati adalah huruf yang terdapat di dada, huruf ini disebut juga dengan rajah kalacakra yang berbunyi : ya maraja, jara maya; ya marani, nira maya; ya silapa,pala siya; ya midora, rada miya; ya midosa, sado miya; ya dayuda, dayu daya; ya sinyaca, caya siya; ya sihama, maha siya. Terjemahannya adalah "Hai Kala yang datang, hilanglah kesaktianmu;yang memberi lapar kenyangkanlah; yang memberi kemelaratan cukupilah; yang menyiksa jangan membuat sengsara; yang memerangi larutlah kekuatanmu; yang jahat berilah belaskasihan; yang menjadi hama jdikanlah cinta kasih (Soetarno, 1995: 28) Sedangkan sastra gigir adalah huruf yang berada di punggung, sastra gigir juga disebut dengan panca wali muka. Sastra gigir mengisahkan tentang asal mula dan terjadinya Kama Salah.

Dengan kata lain dapat dikatakan bahwa Caraka Balik menggambarkan tentang adanya dua sifat yang berbeda yang dimiliki oleh manusia. Sifat ini terdapat pada dahi yang menunjukkan otak manusia, jadi di otak manusia terdapat dua sifat yang berbeda. Hendaknya manusia bisa mengatur dua sifat tersebut. Kemudian sastra telak terdapat pada mulut, hal ini menunjukkan apa yang akan dikatakan oleh manusia berdasarkan pada sesuatu yang berada di otak. Sastra Binedhati terdapat di dada atau hati. Sastra Binedhati berisi tentang doa mengharap kebaikan. Hal ini mengisyaratkan bahwa seharusnya di setiap hati manusia selalu berisi tentang kebaikan, karena apa yang ada di otak akan diolah dihati yang akhirnya akan diucapkan dalam bentuk kata-kata. Sastra gigir yang terdapat pada punggung Bathara Kala menceritakan tentang sejarah terjadinya Bathara Kala. Sesuai dengan namanya, Dhalang Kandhabuwana mampu membaca, menceritakan, dan menerangkan maksud dari semua yang tertulis pada tubuh Bathara Kala.

Lebih lanjut, Dhalang Kandhabuwana adalah transformasi dari Bathara Wisnu, seorang dewa kebenaran yang bertugas menjaga keamanan dan kesejahteraan dunia. Bathara Wisnu dipercaya sebagai nenek moyang orang Jawa. Dialah yang membuka tanah Jawa sehingga memahami seluk-beluk apapun yang terjadi di Jawa. Dhalang Kandhabuwana mempunyai peran yang penting sebagai pembebas manusia sukerta. Dengan kata lain dapat dikatakan 
bahwa orang-orang sukerta dan penganyam-anyam dapat dibebaskan oleh Dhalang Kandhabuwana menjadi manusia normal yang hidupnya tidak dihantui oleh ancaman dengan menyelenggarakan upacara ruwatan.

Manusia normal atau bebas dalam makalah ini menunjukkan kondisi orang-orang sukerta setelah mereka menjalani upacara ruwatan. Semua tokoh sukerta dan penganyam-anyam yang ada dalam teks Murwakala akhirnya terlepas dari ancaman yang menghadang hidup mereka. Tidak semua tokoh diruwat tetapi mereka berhasil keluar dari kondisi suker setelah melakukan upaya, seperti yang dilakukan oleh Jaka Jatusmati dan Truna Bapa sebagai anak ontang-anting.

Jaka jatusmati memahami konsekuensinya sebagai anak ontang-anting, yaitu akan menjadi makanan Bathara Kala, oleh sebab itu, dia mengikuti nasehat ibunya untuk mandi di Telaga Madirda. Dengan mandi di telaga Madirda maka dia akan keluar atau terbebas dari kondisi suker (kondisi yang tidak baik). Ternyata, setelah mandi di telaga Madirda, Jaka Jatusmati bertemu dengan Bathara Kala sehingga terjadilah perang karena Jaka Jatusmati tidak mau dimakan Bathara Kala dan berusaha lari menjauh. Akhirnya, Jaka Jatusmati berhasil lepas dari ancaman Bathara Kala.

Jaka Jatusmati berhasil melarikan diri, kemudian Bathara Kala bertemu dengan Truna Bapa yang juga sebagai anak ontang-anting. Truna Bapa tidak mandi di telaga Madirda namun dia mempunyai tubuh yang lebih perkasa dan kuat dibandingkan dengan Bathara Kala. Truna Bapa melakukan perlawanan ketika Bathara Kala hendak memakannya. Mengakui kekalahannya, akhirnya Bathara Kala tidak berhasil memakan Truna Bapa artinya Truna Bapa berhasil menyelamatkan diri dari ancaman Bathara Kala.

Bathara Kala juga termasuk dalam kelompok sukerta karena dia lahir dengan proses yang salah sehingga dia juga menghadapi ancaman yaitu keinginannya memakan manusia. Untuk itu, Bathara Kala meminta Dhalang Kandhabuwana meruwatnya, karena dia ingin keluar dari kondisinya yang selalu ingin memakan manusia. Dia ingin merasakan kehidupan yang tentram. Ternyata, setelah diruwat, Bathara Kala merasa hidupnya lebih tentram dan tidak ada keinginan untuk memakan manusia lagi. Secara singkat dapat dikatakan bahwa Bathara Kala berhasil keluar dari kondisi suker setelah dia diruwat oleh Dhalang Kandhabuwana.

Bathari Durga akhirnya bisa kembali ke wujud asalnya sebagai Bathari Uma yang mempunyai wajah yang cantik setelah dia diruwat oleh Dhalang Kandhabuwana. Dhalang Kandhabuwana bersedia meruwat Bathari Durga dengan syarat bahwa Bathari Durga harus mampu menjadi wanita yang utama yaitu wanita yang mulia, wanita yang memahami hak dan kuajiban sebagai seorang istri.

Semua tokoh yang mengalami ancaman karena tergolong dalam kelompok sukerta maupun penganyamanyam akhirnya terlepas dari kondisi yang tidak baik. Hal ini memberikan pemahaman bahwa manusia jika ingin mengubah takdirnya maka mereka harus berikhtiar, berusaha keluar dari kondisi tersebut. Orang-orang sukerta dan penganyam-anyam dibebaskan oleh Dhalang Kandhabuwana juga menunjukkan bahwa akhirnya tokoh-tokoh yang lemah diselamatkan oleh tokoh yang kuat atau tokoh yang tidak baik dalam hal ini Bathara Kala dikalahkan oleh tokoh yang baik yaitu Bathara Wisnu.

Setelah menjadi manusia yang bebas yaitu manusia yang bebas dari segala ancaman, maka langkah berikutnya, adalah dimandikan dengan menggunakan air dari tujuh sumber. Peristiwa ini dipresentasikan oleh tokoh Bathara Kala yang dimandikan oleh Dhalang Kandhabuwana dengan menggunakan air dari tujuh sumber. Tujuan mandi adalah membersihan diri dari segala kotoran sehingga diharapkan setelah dimandikan Bathara Kala akan berada dalam kondisi yang bersih lahir dan batin. Bathara Kala setelah dimandikan kemudian diberi nasehat oleh Dhalang Kandhabuwana seperti tertulis di bawah ini :

Dalang :Kala / Kala dèn éling sira / sira mulia marang jati surangan / asalira têka ora / sira mulia marang ora / asalira têka ing jati ya muliha ing jati / ingsun sêjatining wasésa //

Kala, ingatlah kamu. Kembalilah kamu ke kesucian, kamu berasal dari ketidakadaan, kembalilah kamu pada ketidakberadaan itu, kamu berasal dari diri dan pulanglah ke diri, sayalah sebenarnya yang berwewenang memutuskannya.

\section{KESIMPULAN}

Berdasarkan pada pemaparan tentang bagaimana orang Jawa melihat wayang dan bagaimana orang Jawa memiliki pranata-pranata budaya ruwatan maka makna teks Murwakala dapat dikaitkan dengan konsep sangkan paraning dumadi. Konsep ini dapat dijadikan sebagai upaya alternatif untuk mengintropeksi diri sendiri menuju manusia yang lebih baik. Teks lakon Murwakala pada upacara ruwatan tidak hanya memberikan tontonan tetapi juga tuntunan dan tatanan.

Tuntunan dan tatanan dipresentasikan melalui peristiwa yang dialami oleh semua karakter yang ada dalam lakon Murwakala. Peristiwa-peristiwa yang dialami oleh masing-masing tokoh menggambarkan ajaran perilaku atau code of conduct baik yang bersifat positif maupun negatif. Code of conduct tersebut dapat dijadikan pedoman hidup karena berkenaan dengan pembinaan mental dan spiritual, seperti : 1) etika terutama etika yang mengatur hubungan antara suami dan istri bahwa kumpulnya suami dan istri dalam persetubuhan mengandung kewajiban suci dan cita-cita luhur untuk memperoleh wiji-aji atau bibit unggul agar dianugerahi anak yang berbudi baik, berguna untuk keluarga, masyarakat luas, dan peri kemanusiaan, hubungan suami dan istri diwakili oleh hubungan tokoh Batara Guru dengan Batari Uma, hubungan antara orang tua dan anak, diwakili oleh hubungan antara Batara Guru dengan Batara Kala, etika tentang bagaimana melakukan pekerjaan dengan tuntas seperti yang dilakukan oleh orang yang sedang menanak nasi, dan etika atasan dan bawahan yang dipresentasikan oleh hubungan Dalang Kandabawana dan Panjak Kalunglungan, 2) ekonomi yang tercermin dalam jenis mata pencaharian, melalui tokoh maling, Setiap orang tentunya mempunyai pemahaman tertentu bagaimana mencari pekerjaan yang baik, 3) sifat gotong royong yang dijelaskan dengan kehadiran tokoh Suwarno yang ingin meruwat anaknya dengan menyelenggarakan ruwatan masal, 4) sifat disiplin, terutama disiplin dalam penggunaan waktu. 


\section{DAFTAR PUSTAKA}

Abimanyu, Petir. 2014. Mistik Kejawen: Menguak Rahasia Hidup Orang Jawa.Yogyakarta: Palapa.

Abrams, M.H.1981. A Glossary of Literary Terms. New York: Holt, Rinehart andWinston.

Budi Santoso, Iman.2012. Spiritualisme Jawa : Sejarah, Laku, dan Intisari Ajaran. Yogyakarta : Memayu Publishing.

Chamamah Soeratno, Siti. 2011. Sastra, Teori \& Metode. Yogyakarta: Penerbit Elmatera.

Dananjaya, James.1994.Folklor Indonesia.Jakarta:Graffiti Press.

Darmo, Budi. 1990. Perihal Studi Sastra. Basis, tahun XXXIX No. 8 bulan Agustus.

Endraswara, Suwardi. 2012. Falsafah Hidup Jawa: Menggali Mutiara Kebijakan dari Intisari Filsafat Kejawen. Yogyakarta: Cakrawala.

Finnegan, Ruth. 1976. Oral Poetry: Its Nature, Significance and Social Context. Cambridge University Press.

Franchi, Carol Ann. 1980. A Structural Analysis of Gides "Les Caves du Vatican" According to The Theories of Claude Lévi-Strauss. London: The Florida State University. Disertasi dipublikasikan oleh Universitu Microfilms International.

Grimes, Joseph E. 1975. The Thread of Discourse. Paris: Moultan The Hague.

Groenendael, Victorian M. Clara van. 1987. Dalang di Balik Wayang.Jakarta: Pustaka Utama Grafiti.

Haryanto, Sindung. 2013. Dunia Simbol Orang Jawa. Yogyakarta: Penerbit Kepel Press.

Herusatoto, Budiono. 2012. Mitologi Jawa. Jakarta: Oncor Semesta Ilmu.

Hinzler, H.I.R. 1981. Bima Swarga in Balinese Wayang. The Hague: Martinus Nijhoff.

Hobart, Angela. 1987. Dancing Shadows of Bali: Theatre and Myth. London and New York: KPI

Hutomo, Suripan Sadi. 1983. Panduan Penelitian Sastra Lisan/Daerah. Jakarta: Pusat Pembinaan Pengembangan Bahasa.

Kamajaya, Karkono, dkk. 1992.Ruwatan Murwakala: Suatu Pedoman. Yogyakarta: Duta Wacana University Press.

Kasidi. 1995. Lakon Wayang Kulit Purwa Palasara Rabi: Suntingan Teks dan Analisis Struktural. Tesis.

Kenny, William. 1966. How to Analyze Fiction. New York: Monarch Press.

Keeler, Ward. 1992. Release from Kala's Grip: Ritual Uses of Shadow Plays in Java and Bali. JSTOR, pp. 125.http://www.jstor.org/stable/41581000, diakses 1 februari 2015).

Lord, Albert B. 1976. The Singer of Tales. New York: Atheneum.

Maziyah, Siti. 2010. Kontroversi Serat Gatholoco: Pendekatan Teologis Penganut Kejawen dengan Paham Puritan. Yogyakarta: Panji Pustaka.

Mulder, Niels. 2009. Mistisisme Jawa: Idiologi di Indonesia. Yogyakarta: LKiS.

Pamungkas, Ragil. 2008. Tradisi Ruwatan: Misteri di Balik Ruwatan.Jakarta: PT.Buku Kita.

Propp, Vladimir. 1984. Theory and History of Folklore: Theory and History of Literature, vol 5. United Kingdom: Manchester University Press.

Rassers, W.H., 1982. Panji, The Culture Hero: A Structural Study of Religion in Java. The Hague: Martinus Nijhoff.

Sangidu. 2004. Penelitian Sastra: Pendekatan, Teori, Metode, Tehnik, dan Kiat. Yogyakarta: Unit Penerbitan Sastra Asia Barat. Fakultas Ilmu Budaya Universitas Gadjah Mada.

Santoso, Imam Budi. 2011. Laku Prihatin: Investasi menuju Sukses Ala Manusia Jawa. Yogyakarta: Memayu Publishing.

Satoto, Soediro. 1985. Wayang Kulit Purwa: Makna dan Struktur Dramatiknya. Yogyakarta: Proyek penelitian dan Pengkajian Javanologi.

Satoto, Soediro. 2012. Analisis Drama dan Teater. Yogyakarta: Penerbit Ombak.

Subalidinata. At.al.1985. Sejarah dan Perkembangan Cerita Murwakala dan Ruwatan dari sumber-sumber Sastra Jawa. Yogyakarta: Departemen Pendidikan dan Kebudayaan. Direktorat Jendral Kebudayaan.

Sudharto. 2004. "Makna Simbolis dari Seni Pewayangan". Dalam Anasom (ed). Merumuskan Kembali Interelasi Islam Jawa. Yogyakarta: Gama Media.

Soetarno.1995.Ruwatan di Daerah Surakarta.Surakarta: CV. Cendrawasih.

Soetrisno. R. 2008. Wayang Sebagai Warisan Budaya Dunia. Jakarta: Penerbit SIC.

Sukatman. 2009. Butir-butir Tradisi Lisan Indonesia Pengantar Teori dan Pembelajarannya. Yogyakarta: Laksbang Pressindo.

Supriyono, dkk,. 2008. Seni Pedalangan. Jakarta: Direktorat Pembinaan Sekolah Menengah Kejuruan Direktorat Jenderal Manajemen Pendidikan Dasar dan Menengah Departemen pendidikan Nasional.

Sutarjo,Imam. 2010. Keindahan Bahasa Pedalangan.Solo: FSSR Publising.

Sweeney, Amin. 1987. A Full Hearing: Orality and Literacy in the Malay World. London: University of California Press.

Teddy Rusdi, Sri.2012. Ruwatan Sukerta dan Ki Timbul Hadiprayitno. Jakarta: Yayasan Kertagama

Teeuw.A.2003.Sastra dan Ilmu Sastra. Jakarta: P.T. Dunia Pustaka Jaya.

Tutoli, Nani. 1990. (cet.ke-1). Tanggomo: Salah Satu Ragam Sastra Lisan Gorontalo. Jakarta: Intermasa (seri II dep).

Wahyudi, Aris. 2012. Lakon Dewa Ruci Cara menjadi Jawa: Sebuah Analisis Strukturalisme Lévi-Strauss Dalam Kajian Wayang. Yogyakarta: Penerbit Bagaskara.

Wellek, Rene dan Austin Warren. 1956. Theory of Literature. New York: Harcourt, Brace \& World, Inc

Yasasusastra, J Syahban. 2011. Mengenal Tokoh Pewayangan: Biografi, Bentuk dan Perwatakannya. Yogyakarta: Pustaka Mahardika. 